\title{
Dosing and Monitoring of Methadone in Pregnancy: Literature Review
}

\author{
Jennifer R Shiu and Mary H H Ensom
}

\begin{abstract}
Background: The pharmacokinetics of methadone is altered during pregnancy, but the most appropriate dosing and monitoring regimen has yet to be identified.
\end{abstract}

Objective: To review dosing and monitoring of methadone therapy in pregnancy.

Methods: A literature search was performed in several databases (PubMed, MEDLINE, Embase, International Pharmaceutical Abstracts, and the Cochrane Database of Systematic Reviews) from inception to May 2012. The search terms were "methadone", "pregnancy", "pharmacokinetic", "clearance", "metabolism", "therapeutic drug monitoring", and "methadone dosing". Additional papers were identified by searching the bibliographies of primary and review articles. All English-language primary articles related to methadone pharmacokinetics in pregnancy were included. Articles not related to maternal outcomes were excluded.

Results: The literature search yielded 1 case report and 10 studies discussing use of methadone by pregnant women. Methadone pharmacokinetics in pregnancy has been studied in 3 pharmacokinetic trials, and split dosing of methadone in pregnant women has been described in 1 case report and 3 dosing trials. Only 4 trials evaluated monitoring of methadone concentration in pregnancy. The studies included in this review confirm that methadone pharmacokinetics is altered in pregnancy and is potentially correlated with increases in maternal withdrawal symptoms. Insufficient evidence is available to warrant routine monitoring of serum methadone concentrations in pregnant women with opioid dependence.

Conclusions: Few studies of methadone pharmacokinetics and therapeutic drug monitoring are available for pregnant women with opioid dependence. Although it is known that methadone pharmacokinetics is altered in pregnancy, there is insufficient evidence to guide dosage adjustments and serum concentration monitoring. Until further studies are available, regular follow-up of maternal withdrawal symptoms and empiric dosage adjustments throughout pregnancy are still recommended.

Key words: pharmacokinetics, methadone, pregnancy, dosing

\section{RÉSUMÉ}

Contexte : Le comportement pharmacocinétique de la méthadone est modifié durant la grossesse; la posologie la plus adéquate et le suivi nécessaire n’ont pas encore été déterminés.

Objectif : Évaluer la posologie et le suivi thérapeutique de la méthadone durant la grossesse.

Méthodes : Une recherche bibliographique a été effectuée dans plusieurs bases de données (PubMed, MEDLINE, Embase, International Pharmaceutical Abstracts et Cochrane Database of Systematic Reviews) depuis leurs débuts jusqu’au mois de mai 2012. Les termes utilisés pour la recherche étaient : " méthadone ", " grossesse ", " pharmacocinétique ", " clairance ", " métabolisme ", " suivi thérapeutique pharmacologique » et " posologie de la méthadone ». D’autres articles ont été trouvés par suite de recherches dans les bibliographies des articles primaires et des articles de synthèse. Tous les articles primaires de langue anglaise ayant trait au comportement pharmacocinétique de la méthadone durant la grossesse ont été inclus dans l'analyse et les articles non liés à l'issue de la grossesse ont été rejetés.

Résultats : La recherche bibliographique a permis de trouver dix études et une observation clinique sur l'emploi de la méthadone par les femmes enceintes. Le comportement pharmacocinétique de la méthadone durant la grossesse a été examiné dans trois études de pharmacocinétique et l'administration de doses de méthadone fractionnées chez la femme enceinte a été décrite dans une observation clinique et trois études sur la posologie. Seulement quatre études ont évalué la surveillance des concentrations sériques de méthadone durant la grossesse. Les études retenues pour la présente analyse confirment que le comportement pharmacocinétique de la méthadone est modifié durant la grossesse et est potentiellement corrélé à une augmentation des symptômes de sevrage de la mère. Les données sont insuffisantes pour recommander la surveillance systématique des concentrations sériques de méthadone chez les femmes ayant une dépendance aux opioïdes.

Conclusions : Il existe peu d'études portant sur le comportement pharmacocinétique et le suivi thérapeutique pharmacologique de la méthadone chez la femme enceinte ayant une dépendance aux opioïdes. Bien qu'on sache que le comportement pharmacocinétique de la méthadone est modifié durant la grossesse, les données sont insuffisantes pour guider les ajustements posologiques et la surveillance des concentrations sériques de la méthadone. Jusqu'à ce que d'autres études aient été menées, la surveillance périodique des symptômes de sevrage de la mère et les ajustements posologiques empiriques sont recommandés tout au long de la grossesse.

Mots clés : pharmacocinétique, méthadone, grossesse, posologie

[Traduction par l'éditeur] 


\section{INTRODUCTION}

$\mathrm{P}$ regnant women with opioid dependence are at risk for various medical complications that are directly or indirectly related to chronic substance abuse. Narcotic abuse is associated with various psychiatric conditions, notably depression and suicide, as well as malnutrition, anemia, and domestic violence. ${ }^{1,2}$ Such factors are thought to negatively affect the fetus and may contribute to increased rates of numerous obstetric complications such as spontaneous abortion, premature delivery, pre-eclampsia, premature rupture of membranes, septic thrombophlebitis, and postpartum hemorrhage. ${ }^{1-3}$ To minimize the effects of these medical and obstetric complications, methadone maintenance therapy for chronic pain and substance withdrawal is currently the accepted standard treatment for opioid-dependent pregnant women, as recommended by the Center for Substance Abuse Treatment, ${ }^{3}$ the National Institutes of Health, ${ }^{4}$ and the World Health Organization. ${ }^{5}$

In addition to its psychosocial benefits, methadone is the preferred treatment for opioid dependence because of its pharmacokinetic properties, especially its long half-life (20-35 h), which is related to its accumulation in tissue and subsequent slow release into the blood. ${ }^{6}$ This long half-life allows for oncedaily dosing and is thought to prevent the onset of withdrawal symptoms for at least 24 h. ${ }^{1,3}$ Other advantages are that methadone is active when administered orally, is associated with fewer and less severe euphoric and sedating effects, and antagonizes the euphoric effects of other injected or smoked opioid medications. ${ }^{1,3}$ Among the general pharmacokinetic properties of methadone are its lipophilic properties and multicompartmental kinetics, with a volume of distribution of $4.0 \mathrm{~L} / \mathrm{kg}$ (range 1.9-8.0 L/kg). ${ }^{6}$ However, it also crosses the placental membrane, and low concentrations are secreted in breast milk. ${ }^{6}$ As a drug with low hepatic extraction, methadone is eliminated via oxidative biotransformation, mainly by cytochrome P450 isozymes 3A4 and 2B6 (CYP3A4 and CYP2B6) ${ }^{6-8}$ It has a bioavailability of $70 \%-80 \%$, the time to peak concentration is $2.5-6 \mathrm{~h}$, and $87 \%$ (range $81 \%-95 \%$ ) of the drug is bound to $\alpha_{1}$-acid glycoprotein, albumin, and globulin. ${ }^{3,6}$

Several studies have suggested that the dosage of methadone should be increased for pregnant women to ensure maintenance concentrations similar to those in nonpregnant patients. ${ }^{9-11}$ This need for escalating dosages may be explained by the numerous physiologic changes that a woman experiences during pregnancy, which may result in alterations in the pharmacokinetics of methadone, specifically its absorption, distribution, metabolism, and elimination.

Increases in progesterone and estrogen concentrations during pregnancy cause prolongation of gastrointestinal transit times, which may affect the absorption of oral medications.
Prolongation of transit times occurs more frequently and is more pronounced during the third trimester than during the first trimester and the postpartum period. ${ }^{12,13}$ This longer transit time may enhance the absorption of methadone, which may in turn lead to the need for dosage changes. Furthermore, this transient effect on gastrointestinal transit time may lead to methadone overdose in the postpartum period. That is, if methadone absorption is enhanced in the last trimester of pregnancy, giving the same dose (presumably a greater dose than that given in the first trimester) to the mother post partum could lead to higher serum methadone concentrations and toxic effects.

Physiologic changes affecting methadone distribution in pregnancy include increases in total body fluid, blood volume, and body fat. Throughout pregnancy, the total increase in body fluid can be as much as 6-8 L, $80 \%$ of which is distributed into extracellular space and 20\% into intracellular space. ${ }^{14}$ By week 40 of pregnancy, this translates into a gain of as much as $7.5 \mathrm{~kg} .{ }^{14}$ Although this gain in fluid alone may not be sufficient to alter serum concentrations of methadone, there are also alterations in plasma volume during pregnancy. Whereas the plasma volume of a nonpregnant woman is about $2.6 \mathrm{~L}$, by week 40 of pregnancy, this volume has increased to $3.6 \mathrm{~L}$, resulting in a change in total blood volume from $4 \mathrm{~L}$ to $5.3 \mathrm{~L}$. This increase in total blood volume could result in lower serum methadone concentrations later in pregnancy (because of dilution). ${ }^{14}$ Additionally, increases in body fat during pregnancy could affect the accumulation of methadone. On average, women gain 3 to $4 \mathrm{~kg}$ of fat during pregnancy. ${ }^{14}$ This could lead to further accumulation of methadone in fatty depots, which in turn could result in erratic methadone release affecting methadone serum concentrations. The issue of methadone accumulation is probably a more important problem in the postpartum period when the excess fat is metabolized, a process that releases any accumulated drug. ${ }^{14}$

Because methadone is highly protein-bound, changes in serum protein binding during pregnancy may affect total serum methadone concentrations. For example, methadone is primarily bound to $\alpha_{1}$-acid glycoprotein, which decreases by about 30\% from the first to the third trimester of pregnancy. ${ }^{14}$ Therefore, an increase in the free fraction of methadone and a decrease in total concentration of methadone would be expected. However, the free concentration (i.e., pharmacologically active moiety) would not be expected to change. In addition, albumin decreases by approximately $30 \%$, whereas globulins increase by $15 \%$ over the same period. Although methadone is bound to a lesser extent to these 2 proteins, the net effect of these protein changes is likely to be an increase in the free fraction of methadone.

The mechanism of increased methadone metabolism in pregnancy is thought to be due to hepatic and intestinal induc- 
tion of CYP3A4, which increases enzyme activity. ${ }^{15}$ Because methadone is partly metabolized by CYP3A4, the increase in enzyme activity could also reduce concentrations of free and total methadone during pregnancy.

Although these alterations in methadone pharmacokinetics during pregnancy may result in changes in methadone concentrations, serum methadone monitoring is not routine for pregnant women. Instead, clinicians typically adjust the methadone dose throughout pregnancy according to signs and symptoms of opioid overmedication (e.g., sedation, flushing, hypothermia, bradycardia, low respiratory rate) or withdrawal (e.g., irritability, anxiety, insomnia, muscle aches, shaking, illicit opioid use, tachycardia). ${ }^{3}$ Ideally, the goal of methadone dose adjustment is to avoid signs and symptoms of overmedication or withdrawal throughout pregnancy.

Given the pregnancy-related alterations in methadone pharmacokinetics described above, the most appropriate methadone dosing and monitoring regimen requires assessment. Therefore, the purpose of this analysis was to summarize the effect of pregnancy on the pharmacokinetics of methadone, to review the effects of alternative methadone dosing regimens, to review the relationship between methadone concentrations and the patient's response to therapy, and to evaluate whether monitoring of serum methadone concentrations in pregnancy is warranted.

\section{LITERATURE REVIEW}

A literature search was conducted in several databases (PubMed, from 1947 to May 2012; MEDLINE, from 1946 to May 2012; Embase, from 1980 to May 2012; International Pharmaceutical Abstracts, from 1970 to May 2012; and Cochrane Database of Systematic Reviews, from 2005 to May 2012) using the search terms "methadone", "pregnancy", "pharmacokinetic", "clearance", "metabolism", "therapeutic drug monitoring", and "methadone dosing". Additional papers were identified by searching the bibliographies of primary and review articles. All English-language primary articles related to methadone pharmacokinetics in pregnancy were included in this review; articles not related to maternal outcomes were excluded.

The literature search yielded 1 case report ${ }^{16}$ and 10 studies ${ }^{9-11,17-23}$ discussing the use of methadone in pregnant women. Methadone pharmacokinetics in pregnancy was studied in 3 pharmacokinetic trials, ${ }^{9-11}$ and split dosing of methadone in pregnant women was described in the case report ${ }^{16}$ and in 3 dosing trials. ${ }^{17-19}$ Only 4 trials evaluated measurement of methadone concentrations in pregnancy. ${ }^{20-23}$

\section{Methadone Pharmacokinetics in Pregnancy}

As summarized above, alterations in methadone pharmacokinetics have been observed during pregnancy. Additional details of the 3 pharmacokinetic trials are provided here. In a longitudinal within-subject study, Pond and others investigated the effect of pregnancy on methadone pharmacokinetics in 9 pregnant women (mean age \pm standard deviation $26 \pm 3$ years, mean duration of methadone maintenance therapy $1.4 \pm$ 0.9 years). Serum methadone concentrations were measured between 20 and 34 weeks (phase I) and between 35 and 40 weeks (phase II) of gestation, and between 1 and 4 weeks (phase III) and between 8 and 9 weeks (phase IV) postpartum. Methadone concentrations reported for phases II, III, and IV were compared with the methadone doses $(\mathrm{mg} / \mathrm{kg})$ given in phase I. Trough methadone concentrations were lower in phases I and II than in phases III and IV $(0.11 \pm 0.05$ and $0.19 \pm 0.18 \mu \mathrm{mol} / \mathrm{L}$ versus $0.30 \pm 0.20$ and $0.33 \pm 0.20$ $\mu \mathrm{mol} / \mathrm{L})$. Time to peak methadone concentration did not change between phases $(2.0 \pm 0.8 \mathrm{~h}$ in phase I, $2.1 \pm 1.2 \mathrm{~h}$ in phase 2, $2.1 \pm 0.9 \mathrm{~h}$ in phase 3 , and $2.1 \pm 0.8 \mathrm{~h}$ in phase IV). Weight-adjusted total clearance was higher in phases I and II than in phases III and IV $\left(4.9 \pm 1.9\right.$ and $3.9 \pm 1.7 \mathrm{~mL} \mathrm{~min}^{-1} \mathrm{~kg}^{-1}$ versus $2.7 \pm 1.3$ and $\left.2.7 \pm 1.6 \mathrm{~mL} \mathrm{~min}^{-1} \mathrm{~kg}^{-1}\right)$. Methadone renal clearance was also higher in phases I and II than in phases III and IV $(22 \pm 8$ and $21 \pm 16 \mathrm{~mL} / \mathrm{min}$ versus $13 \pm 6$ and $11 \pm 5 \mathrm{~mL} / \mathrm{min})$. During the second and third trimesters of pregnancy, increased excretion of urinary methadone metabolites and lower methadone serum concentrations corresponded with maternal withdrawal effects. ${ }^{9}$

Jarvis and others ${ }^{10}$ compared 23 pregnant women (mean age $29 \pm 4$ years, mean gestational age $28 \pm 5$ weeks) and 16 nonpregnant women (mean age $38 \pm 7$ years), all with opioid dependence, to determine changes in methadone pharmacokinetics during pregnancy. The mean elimination rate constant was numerically higher in pregnant than nonpregnant women $\left(0.078 \mathrm{~h}^{-1}\right.$ versus $\left.0.042 \mathrm{~h}^{-1} ; p=0.12\right)$, as were time to peak methadone concentrations $(5.3 \mathrm{~h} \pm 7.5$ versus $2.8 \pm 1.3 \mathrm{~h}$; $p=0.32)$ and apparent distribution volume $(165 \pm 36 \mathrm{~L}$ versus $144 \pm 41 \mathrm{~L}[2.2 \mathrm{~L} / \mathrm{kg}$ versus $2.3 \mathrm{~L} / \mathrm{kg}] ; p=0.21$ ). The ratio of apparent clearance to bioavailability was also higher in pregnant than nonpregnant patients $(148 \pm 53 \mathrm{~mL} / \mathrm{min}$ versus $95 \pm 56$ $\mathrm{mL} / \mathrm{min} ; p=0.05)$. None of these results reached statistical significance. Four of the pregnant women had reduced bioavailability (52\%), which indicates that the apparent clearance was unchanged and that the change in apparent clearance over bioavailability resulted from reduced bioavailability during pregnancy. Furthermore, the results of the study were uninterpretable, because some of the patients were not at steady state and there was no wash-out period for women who were consuming heroin or other illicit substances before study entry.

In a longitudinal study conducted at the Leeds Addiction Unit, Wolff and others ${ }^{11}$ evaluated the rate of methadone clearance throughout pregnancy and after birth. Nine pregnant women with opioid dependence (mean age 22.8 years) had 
serum samples drawn for measurement of trough methadone concentrations just before the usual daily dose during each trimester and after birth. The methadone dose was $0.72 \pm 0.83$ $\mathrm{mg} / \mathrm{kg}$ in the first trimester ( $0-13$ weeks), $0.40 \pm 0.62 \mathrm{mg} / \mathrm{kg}$ in the second trimester (14-27 weeks), $0.28 \pm 0.44 \mathrm{mg} / \mathrm{kg}$ in the third trimester (28-40 weeks), and $0.16 \pm 0.45 \mathrm{mg} / \mathrm{kg}$ in the postpartum period. Trough serum concentration decreased from the first to the third trimester $(0.37 \pm 0.31,0.36 \pm 0.35$, and $0.23 \pm 0.25 \mu \mathrm{mol} / \mathrm{L}$ in the first, second, and third trimesters, respectively) but increased postpartum $(0.73 \pm 0.78$ $\mu \mathrm{mol} / \mathrm{L})$. The same pattern held for area under the curve: 14.53 $\pm 16.28,12.18 \pm 11.6$, and $7.07 \pm 8.11 \mu \mathrm{mol} \bullet \mathrm{h} / \mathrm{L}$ in the first, second, and third trimesters, respectively, and $19.93 \pm 18.67$ $\mu \mathrm{mol} \bullet \mathrm{h} / \mathrm{L}$ postpartum. Weight-adjusted clearance increased throughout pregnancy $(2.83 \pm 3.00,3.17 \pm 3.50$, and $3.50 \pm$ $3.50 \mathrm{~mL} \mathrm{~min}{ }^{-1} \mathrm{~kg}^{-1}$ in the first, second, and third trimesters, respectively) but decreased postpartum $\left(1.83 \pm 1.00 \mathrm{~mL} \mathrm{~min}{ }^{-1} \mathrm{~kg}^{-1}\right)$. A limitation of this study was that serum methadone concentrations could not be obtained for all 9 patients in all 4 periods: data were collected from 4 patients for the first and second trimesters, from 8 patients for the third trimester, and from 3 patients for the postpartum period. Given the already small sample size, the missing data may have affected reliability of the results. Another limitation was that patients continued to use heroin, cannabis, crack cocaine, benzodiazepines, and/or alcohol during pregnancy, which may have confounded the results (although providing a reflection of real world practice).

It is difficult to compare the normalized concentrations from the study performed by Jarvis and others ${ }^{10}$ with the mean concentrations (based on differing doses) measured by Wolff and others. ${ }^{11}$ For example, increases in weight-adjusted clearance values throughout pregnancy may simply reflect reductions in bioavailability.

These studies demonstrating altered methadone pharmacokinetics in pregnancy support the practice of increasing methadone dosages, especially during the third trimester of pregnancy, as a way to maintain methadone levels. However, the optimal methadone dosage range and regimen for pregnant women are unclear, and there are insufficient data from these studies to suggest that constant methadone levels were achieved by the dosing adjustments that were made.

\section{Methadone Dosing in Pregnancy}

Changes in methadone pharmacokinetics during pregnancy have several implications for dosing. Swift and others ${ }^{16}$ investigated the effects of split dosing of methadone in a pregnant 24-year-old woman who had been receiving a maintenance dose of $30 \mathrm{mg} /$ day for 4 months. During month 8 of the pregnancy, she reported severe withdrawal symptoms 10-12 h after her daily methadone dose. Data on serum concentration as a function of time after her daily dose were fit to a one-compart- ment model, to generate estimates of methadone clearance $(473 \mathrm{~mL} / \mathrm{min})$, distribution volume $(343.2 \mathrm{~L})$, elimination rate constant $\left(0.085 \mathrm{~h}^{-1}\right)$, and half-life $(8.1 \mathrm{~h})$. By extrapolating the data to $24 \mathrm{~h}$, the authors estimated that more sustained serum concentrations could be achieved by splitting the 30-mg methadone dose into two 15 -mg doses, to be given at 12 -h intervals, than by increasing the daily dose by $50 \%$ (to $45 \mathrm{mg}$ ). Simulated peak methadone concentrations were 0.25 , 0.17 , and $0.37 \mu \mathrm{mol} / \mathrm{L}$ for the $30-, 15-$, and $45-\mathrm{mg}$ doses, respectively, and simulated trough methadone concentrations were $0.03,0.06$, and $0.05 \mu \mathrm{mol} / \mathrm{L}$, respectively. One limitation was that the analysis was based on a single patient's data and therefore might not be generalizable to other pregnant women. In addition, the data were simulated, and the methadone concentrations were not correlated with pharmacodynamic outcomes such as alleviation of withdrawal symptoms.

Jansson and others ${ }^{17}$ used a counterbalanced study design to compare the effects of split dosing and single-dose administration of methadone on fetal and maternal outcomes in 40 pregnant women receiving maintenance methadone therapy. Data on heart rate, variability in heart rate, vagal tone, and skin conductance were collected. All participants (mean age $28.1 \pm$ 5.4 years) were recruited at 32 weeks gestational age, and the average daily methadone maintenance dose was $72.9 \pm 19.6$ mg. Fetal and maternal monitoring was conducted during the maternal methadone trough ( $1 \mathrm{~h}$ before the morning dose) and peak ( $2.5 \mathrm{~h}$ after morning dose), with sampling performed during weeks 36 and 37 of pregnancy. Half of the women $(n=20)$ were receiving a single daily dose at 36 weeks and a split dose at 37 weeks gestational age, whereas the other half $(n=20)$ were receiving a split dose at 36 weeks and a single dose at 37 weeks. For monitoring at maternal methadone peak, fetal heart rate was higher with a split dose than with a single daily dose $(133.39 \pm 1.29$ versus $130.39 \pm 8.75$ beats $/ \mathrm{min})$, as were fetal heart rate variability $(4.58 \pm 1.29$ versus $4.11 \pm 1.51)$ and motor activity values $(5.64 \pm 2.21$ versus $4.63 \pm 1.41)$. Only maternal heart rate variability $(0.053 \pm 0.023$ versus $0.048 \pm$ 0.020) was higher at peak concentrations with single-dose therapy. There were no differences in maternal vagal tone or skin conductance. Although the authors concluded that split dosing of methadone is associated with less suppression of fetal neurobehaviours (specifically fetal heart rate, heart rate variability, and motor activity), it is difficult to determine whether this effect is clinically meaningful. The study did not provide sufficient information about maternal withdrawal symptoms experienced, and none of the differences in maternal monitoring parameters (with the exception of maternal heart rate variability) were statistically significant. Notably, women enrolled in the study were compliant with their methadone treatment and were not abusing illicit substances or alcohol and may therefore not be representative of all pregnant women with opioid dependence. 
DePetrillo and Rice ${ }^{18}$ found that split dosing of methadone was associated with greater compliance with requests to present for urinalysis. This retrospective cohort study comparing once-daily dosing and split dosing involved 45 pregnant women (28-30 years old) who entered an outpatient methadone maintenance program between 5 and 15 weeks gestational age, with an entry methadone dose between 33 and $44 \mathrm{mg} /$ day. Patients self-selected their methadone dosing regimen: either once-daily dosing or split (twice-daily) dosing. There were no significant differences between the 2 groups in terms of opiate or cocaine use in the first and second trimesters or opiate use in the third trimester. Also, no difference was observed in terms of noncompliance with requests to present for urine toxicology testing in the second trimester. Noncompliance in the first trimester was greater within the split-dosing group than the once-daily dosing group; however, the authors did not report rates of noncompliance by group. The only significant differences between dosing groups occurred in the third trimester, when the split-dosing group had significantly less cocaine use than the once-daily dosing group $(0.3 \%$ versus $15.3 \%)$ and lower rates of noncompliance with requests for urine toxicology testing $(0.5 \%$ versus $23.8 \%)$. This study was limited by its retrospective nature, and the results may have been biased by the self-selection of patients into each dosing group. In addition, it was not known if rates of opiate and cocaine use reported in this study were reliable, as there was a high rate of noncompliance with urine toxicology testing in the daily-dosing group. However, the study did provide support for improvements in compliance with an outpatient methadone program during the third trimester of pregnancy for patients maintained on a split-dose methadone regimen.

From this small body of evidence, it is reasonable to initiate methadone therapy for pregnant women, or to switch them to a split-dosing regimen to maintain more sustained serum methadone concentrations and increase patient compliance with outpatient programs. However, split-dosing regimens introduce a variety of logistic concerns such as decreased convenience for the patient, increased workload for the pharmacist preparing the prescription, and potentially increased risk of methadone diversion if the pharmacist does not observe ingestion of both daily doses. These concerns may limit the application of split dosing in clinical practice.

The need for increasing maintenance methadone doses in pregnant woman was reported by Albright and others. ${ }^{19}$ This retrospective, longitudinal case series followed 139 women (age $18-45$ years) who were receiving methadone before 26 weeks gestational age. Methadone was initiated at $30 \mathrm{mg}$ daily, with an additional 5 to $10 \mathrm{mg}$ administered daily as needed for withdrawal symptoms. A physician or nurse practitioner could increase the dose by $5 \mathrm{mg}$ daily in cases of moderate or severe withdrawal, as assessed by the Clinical Opiate Withdrawal
Scale. The authors found that for $86 \%$ of the women, the methadone dose was increased as gestation advanced, with the mean initial maintenance dose of $69 \mathrm{mg}$ (range $8-160 \mathrm{mg}$ ) being increased to a mean of $93 \mathrm{mg}$ (range 12-185 mg) at delivery (mean change $24 \mathrm{mg}$, $95 \%$ confidence interval $20-28$ $\mathrm{mg}, p<0.001$ ). The increased dosages were continued until 6 weeks postpartum. The results of this study supported the idea that higher maintenance doses of methadone are required during pregnancy, but it did not provide guidance on dosage titration. The study was limited because not all of the patients were compliant with methadone therapy, and the investigators were unable to control the use of supplemental methadone obtained through other means. However, it did show that escalating methadone maintenance doses are required to alleviate maternal withdrawal during pregnancy.

\section{Monitoring of Methadone Concentrations in Pregnancy}

Evidence supporting monitoring of methadone concentrations in pregnancy is limited. Measuring serum methadone concentrations is controversial, as the relationship between methadone concentration and effect in patients with opioid dependence is not well defined. If a dose-concentration relationship is found, serum methadone monitoring may be unnecessary, as empiric dosage adjustments would be sufficient. Wolff and others ${ }^{20}$ developed a high-performance liquid chromatography assay for measuring serum concentration of methadone, to allow examination of the relationship between dose and serum concentrations. Thirty-one patients attending the Leeds Addiction Unit and receiving a stable dosage of methadone (range 3-100 mg daily) were followed over 30 months. Although pregnancy was not explicitly mentioned, the authors of the current review assumed that none of the patients were pregnant. A linear relationship was found between serum concentration and methadone dose, with an average increase of $0.85 \mu \mathrm{mol} / \mathrm{L}$ in concentration for each $1 \mathrm{mg} / \mathrm{kg}$ consumed $(y=0.002+0.263 x, r=0.89, p<0.001)$. However, the authors stated that 5 patients had anomalous serum concentrations of methadone, and for these patients the relationship was not well described by this equation. Wolff and others ${ }^{20}$ speculated that some of these spurious findings were due to illicit ingestion of supplemental methadone, but this did not fully explain the abnormalities observed. Therefore, this model may not be applicable to people with opioid dependence.

Torrens and others ${ }^{21}$ showed that serum concentrations of methadone and D,L-2-ethylidene-1,5-dimethyl-3,5-diphenylpyrrolidine (EDDP), the main (albeit inactive) metabolite of methadone, were not well correlated with heroin use or withdrawal symptoms. The study involved 93 patients (mean age $32.1 \pm 6.7$ years, $73 \%$ male) who were receiving a mean methadone dose of $87 \pm 46 \mathrm{mg} /$ day, with a mean length of 
methadone maintenance treatment of $21.6 \pm 10.4$ months. Although methadone doses did correlate with serum concentrations $(r=0.43, p<0.0005)$, serum EDDP concentrations did not $(r=0.16, p>0.05)$. Also, methadone and EDDP serum concentrations were not significantly different between patients who consumed heroin and those who did not (methadone $1.15 \pm 0.70 \mu \mathrm{mol} / \mathrm{L}$ versus $1.19 \pm 0.70 \mu \mathrm{mol} / \mathrm{L}$, $p>0.05$; EDDP $0.16 \pm 0.09 \mu \mathrm{mol} / \mathrm{L}$ versus $0.17 \pm 0.13$ $\mu \mathrm{mol} / \mathrm{L}, p>0.05)$, and no correlation was found between scores on the short opiate withdrawal scale and serum concentrations of methadone $(r=0.02, p>0.05)$ or $\operatorname{EDDP}(r=-14$, $p>0.05)$. Although this study showed no relationship between serum methadone and EDDP concentrations and pharmacodynamic parameters, its applicability to the current analysis is limited, as the study did not include any pregnant women.

Drozdick and others ${ }^{22}$ investigated the utility of measuring methadone trough concentrations in pregnancy to determine the trough concentration required to prevent withdrawal symptoms and to determine if trough concentrations differed between symptomatic and asymptomatic women. In this blinded prospective observational study, 58 pregnant women with heroin addiction (mean age $27.8 \pm 6.4$ years) had measurement of serum trough concentration of methadone (20-24 h after last dose) in each trimester of pregnancy. The mean trough concentration was statistically different between asymptomatic and symptomatic patients $(0.95 \pm 0.52 \mu \mathrm{mol} / \mathrm{L}$ versus $0.57 \pm$ $0.36 \mu \mathrm{mol} / \mathrm{L}, p<0.0001)$. In the subgroups with negative and positive results on urine toxicology screening, mean trough concentrations were also statistically different between asymptomatic and symptomatic patients (negative subgroup: $1.00 \pm$ $0.50 \mu \mathrm{mol} / \mathrm{L}$ versus $0.60 \pm 0.42 \mu \mathrm{mol} / \mathrm{L}, p=0.004$; positive subgroup: $0.92 \pm 0.53 \mu \mathrm{mol} / \mathrm{L}$ versus $0.55 \pm 0.33 \mu \mathrm{mol} / \mathrm{L}$, $p=0.003)$. The investigators determined that the serum methadone trough concentration required to prevent withdrawal symptoms was $0.78 \mu \mathrm{mol} / \mathrm{L}$ (sensitivity $57 \%$, specificity $81 \%$ ). While $0.78 \mu \mathrm{mol} / \mathrm{L}$ may be a useful target trough concentration in methadone dose titration, the relationship between an increase in methadone dose and an increase in serum concentration remains to be defined for pregnant women, which limits the utility of these findings.

Barnes and others ${ }^{23}$ investigated methadone excretion in sweat (collected by weekly sweat patches) as a possible alternative to serum or urine testing. The study included 29 women (mean age $30.1 \pm 5.3$ years) between 9 and 29 weeks of gestation, with a mean baseline methadone dose of $39.0 \pm 3.9$ $\mathrm{mg} /$ day. The methadone concentration could be detected in all collected sweat patches, but the correlation between dose and patch concentration was weak $(r=0.224)$. Also, for only 75 of 150 consecutive patches tested did the methadone patch concentration reflect dosage adjustments. This study demonstrated that sweat patches are unlikely to be useful in therapeutic drug monitoring. Sweat patches may be helpful in assessing compliance with methadone therapy, but the applicability of these results is limited by the small sample size and large variability both within and between participants.

\section{CONCLUSIONS}

Methadone maintenance remains the standard of care for pregnant women with opioid dependence, but clinical management of this subpopulation is difficult. In addition to increases in medical and obstetric complications associated with continued opioid abuse throughout gestation, methadone pharmacokinetics is altered in pregnancy, which may lead to an increase in maternal withdrawal symptoms. Methadone absorption and distribution may be affected by alterations in gastrointestinal absorption, by increases in total body fluid, blood volume, and body fat, and by changes in protein binding throughout pregnancy. Additionally, methadone metabolism is increased because of induction of the CYP3A4 isozyme, which may alter serum methadone concentrations during pregnancy. Relative to the postpartum period, methadone clearance increases from the first to the third trimesters, correlating with decreased methadone trough concentrations, and it is unclear whether it is more appropriate to increase the methadone dose or to initiate split dosing. Split-dosing regimens in pregnancy are thought to be beneficial in maintaining a more sustained serum concentration of methadone and improving patients' compliance with methadone maintenance programs.

Currently, monitoring serum methadone concentration in pregnant women with opioid dependence does not appear to be warranted, as the relationship between methadone concentration and effect is unclear. Evidence regarding methadone maintenance in this population is sparse, so further research regarding dosage adjustments, therapeutic range, and the relationship between serum concentration and response is required. Although a target trough concentration of 0.78 $\mu \mathrm{mol} / \mathrm{L}$ may be used for titrating the methadone dose, the relationship between an increase in dose and any increase in serum concentration of the drug remains to be defined for pregnant women. Although methadone pharmacokinetics appears to be altered during pregnancy, there is insufficient evidence to suggest that routine measurement of serum methadone concentrations would provide additional benefit over the current practice of regular follow-up of maternal withdrawal symptoms and dosage adjustments throughout pregnancy.

\section{References}

1. Kaltenbach, K, Berghella V, Finnegan L. Opioid dependence during pregnancy. Effects and management. Obstet Gynecol Clin North Am 1998;25(1):139-151.

2. Archie C. Methadone in the management of narcotic addiction in pregnancy. Curr Opin Obstet Gynecol 1998;10(6):435-440. 
3. Center for Substance Abuse Treatment. Medication-assisted treatment for opioid addiction in opioid treatment programs. Treatment Improvement Protocol Series No. 43. Rockville (MD): Substance Abuse and Mental Health Service Administration (US); 2005 [cited 2012 Mar 20]. Available from: www.ncbi.nlm.nih.gov/books/NBK64164/

4. Effective medical treatment of opiate addiction. NIH consensus development conference statement November 17-19, 1997. Rockville (MD): National Institutes of Health; 1997 [cited 2011 Mar 20]. Available from: www.ncbi.nlm.nih.gov/books/NBK15146/

5. Uchtenhagen A, Ladjevic T, Rehm J. WHO guidelines for psychosocially assisted pharmacological treatment of persons dependent on opioids. Geneva (Switzerland): World Health Organization; 2007 [cited 2011 Mar 20]. Available from: www.who.int/substance_abuse/activities/background_ paper.pdf

6. Lugo RA, Satterfield KL, Kern SE. Pharmacokinetics of methadone. J Pain Palliat Care Pharmacother 2005;19(4):13-24.

7. Inturrisi CE, Colburn WA, Kaiko RF, Houde RW, Foley KM. Pharmacokinetics and pharmacodynamics of methadone in patients with chronic pain. Clin Pharmacol Ther 1987;41(4):392-401.

8. Kharasch ED, Hoffer C, Whittington D, Sheffels P. Role of hepatic and intestinal cytochrome P450 3A and 2B6 in the metabolism, disposition, and miotic effects of methadone. Clin Pharmacol Ther 2004;76(3): 250-269.

9. Pond SM, Kreek MJ, Tong TG, Raghunath J, Benowitz NL. Altered methadone pharmacokinetics in methadone-maintained pregnant women. J Pharmacol Exp Ther 1985;233(1):1-6.

10. Jarvis MAE, Wu-Pong S, Kniseley JS, Schnoll SH. Alterations in methadone metabolism during late pregnancy. J Addict Dis 1999;18(4):51-61.

11. Wolff K, Boys A, Rostami-Hodjegan, Hay A, Raistrick D. Changes to methadone clearance during pregnancy. Eur J Clin Pharmacol 2005; 61(10):763-768.

12. Wald A, Van Thiel DH, Hoechstetter L, Gavaler JS, Egler KM, Verm R, et al. Effect of pregnancy on gastrointestinal transit. Dig Dis Sci 1982; 27(11):1015-1018.

13. Chilorio M, Darconza G, Piccioli E, De Carne M, Clemente C, Riezzo G. Gastric emptying and orocecal transit time in pregnancy. J Gastroenterol 2001;36(8):538-543.

14. Pavek P, Ceckova M, Staud F. Variation of drug kinetics in pregnancy. Curr Drug Metab 2009;10(5):520-529.

15. van Heeswijk RP, Khaliq Y, Gallicano KD, Bourbeau M, Seguin I, Philips EJ, et al. The pharmacokinetics of nelfinavir and M8 during pregnancy and post partum. Clin Pharmacol Ther 2004;76(6):588-597.

16. Swift RM, Dudley M, DePetrillo P, Camara P, Griffiths W. Altered methadone pharmacokinetics in pregnancy: implications for dosing. $J$ Subst Abuse 1989;1(4):453-460.
17. Jansson LM, DiPietro JA, Velez M, Elko A, Knauer H, Kivlighan KT. Maternal methadone dosing schedule and fetal neurobehavior. J Matern Fetal Neonatal Med 2009;22(1):29-35.

18. DePetrillo PB, Rice JM. Methadone dosing and pregnancy: impact on program compliance. Int J Addict 1995;30(2):207-217.

19. Albright B, de la Torre L, Skipper B, Price S, Abbott P, Rayburn W. Changes in methadone maintenance therapy during and after pregnancy. J Subst Abuse Treat 2011;41(4):347-353.

20. Wolff K, Sanderson M, Hay AWM, Raistrick D. Methadone concentrations in plasma and their relationship to drug dosage. Clin Chem 1991;37(2):205-209.

21. Torrens M, Castillo C, San L, del Moral E, González ML, de la Torre R. Plasma methadone concentrations as an indicator of opioid withdrawal symptoms and heroin use in a methadone maintenance program. Drug Alcohol Depend 1998;52(3):193-200.

22. Drozdick J 3rd, Berghella V, Hill M, Kaltenbach K. Methadone trough levels in pregnancy. Am J Obstet Gynecol 2002;187(5):1184-1188.

23. Barnes AJ, Brunet BR, Choo RE, Mura P, Johnson RE, Jones HE, et al. Excretion of methadone in sweat of pregnant women throughout gestation after controlled methadone administration. Ther Drug Monit 2010; 32(4):497-503.

Jennifer R Shiu, BSCPharm, PharmD, ACPR, is a Clinical Practice Leader, Alberta Health Services - Pharmacy Services, Edmonton, Alberta, Canada.

Mary H H Ensom, BS(Pharm), PharmD, FASHP, FCCP, FCSHP, FCAHS, is Professor, Faculty of Pharmaceutical Sciences, and Distinguished University Scholar, University of British Columbia, and Clinical Pharmacy Specialist, Children's and Women's Health Centre of British Columbia, Vancouver, British Columbia. She is also the Editor of the CJHP.

\section{Address correspondence to:}

Dr Mary $\mathrm{H} \mathrm{H}$ Ensom

Department of Pharmacy (OB7)

Children's \& Women's Health Centre of British Columbia

4500 Oak Street

Vancouver BC V6B 6E4

e-mail: ensom@mail.ubc.ca

\section{CISADL 20 I 2}

\section{Order your copy of the 2012 Canadian Investigational \& Special Access Drug List today!}

\section{Please use the CSHP order form found online at CSHP.ca to place your order:}

\section{http://www.cshp.ca/productsServices/otherPublications/canadianInvestigational e.asp}

The CISADL is a compilation of drugs that are currently not marketed in Canada and may have Investigational or Special Access status with Health Canada. This list is not endorsed by Health Canada's Special Access Program. For precise information about the regulatory status of a drug, contact the Special Access Program directly. Entries to the list are contributed to by several Drug Information Centres across Canada and by Canadian drug manufacturers. In cases where non-marketed drugs do not appear on the list, foreign references should be consulted. The content of the list includes generic name and strength/concentration, dosage form, pharmacology/therapeutic use, trade and code name, source (manufacturer/distributor), and comments. Available in English only.

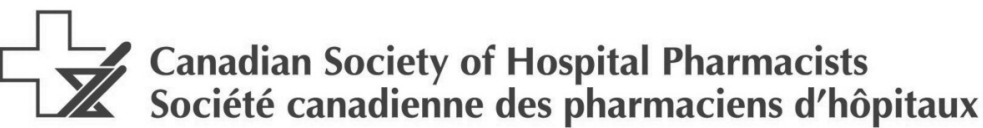

